
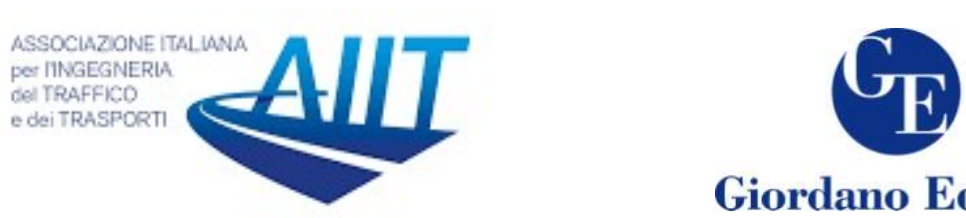

Giordano Editore

\title{
The Effects of Driver Age and Gender on Vehicle Stopping Distance Under Different Speeds
}

\author{
Majid Farag Hichim ${ }^{1}$, Ahmed Shany Khusheef ${ }^{2 *}$, Saddam Hasan \\ Raheemah $^{1}$ \\ ${ }^{1}$ Department of Technical Automobile, Kut Technical Institute, \\ Middle Technical University, Baghdad, IRAQ \\ ${ }^{2}$ Department of Electrical Techniques, Kut Technical Institute, \\ Middle Technical University, Baghdad, IRAQ
}

\begin{abstract}
This study was conducted to estimate the stopping distance that is needed to halt a vehicle at different speeds. In order to improve the equality of evaluation, age and gender of the drivers, which affects the reaction times (RTs), were taken into consideration. The measurements of the RTs in a simulated driving environment were executed and the acquired results were statistically analyzed using "Statistical Package for the Social Sciences" (SPSS). The results indicate that participants' ages and genders had a significant relationship with the RTs as P-values $<0.01$ and 0.022 , respectively. Then, the Analysis of Variance (ANOVA) was conducted to compare the effect of the predictors' ages, genders, and vehicle's speeds on the vehicle's stopping distance. The overall regression model showed that these predictors had a high significant effect on stopping distance as $\mathrm{F}(3,46)=777.05$, $\mathrm{P}$-value $<0.01$, and R-square $=0.98$. However, gender exclusively was not significant as its P-value $>0.24$.
\end{abstract}

Keywords: Reaction Time, Driver Age and Gender, Vehicle Stopping Distance, Braking Distance

\section{Introduction}

When a vehicle is travelling on a road, it is important for the driver to estimate the stopping time and distance in order to avoid road accident. The stopping time is the time that is necessary to control the vehicle until it stops and it is divided into two main parts: the reaction time (RT) and braking time (Evans and Pitkethly, 2011). RT is the most important feature used in traffic accident analysis (Bucsuházy and Semela, 2017). The reaction time of the driver is determined from the moment of perception of hazard to the moment of reaction to the situations, "either by steering or braking" (Olson, 1989; Magister et al., 2006). This depends on several factors such as psychological state of the

*Corresponding author: Ahmed Shany Khusheef(ahmed_shany@yahoo.com) 
driver, which is subjected to many circumstances and emotions that require constant focus and the ability to control the appropriate reaction without tension or anxiety. Also, it was discovered that the chance of accidents increase with stress, as it affects the level of focus that is needed to deal with surprises while driving. The driving conditions and the traffic situations also influence drivers' RTs (Magister et al., 2006; Rievaj et al., 2013). For most drivers, the RTs "in case of appearance of a sudden obstacle" are between 0.80 and $1.8 \mathrm{~s}$ (Olson, 1989); and it can be increased up to $3 \mathrm{sec}$ by "special conditions (such as night or impact)" (Limpert, 1984). The RTs are also influenced by the age differences of the people (Bucsuházy and Semela, 2017; Deary and Der, 2005; Hultsch et al., 2002). For instance, Inui, (1997) and Porciatti et al. (1999) confirmed that "reaction times (RTs) to simple sensory stimuli (auditory stimuli or light flashes) are known to increase with age". However, young drivers are more frequently involved in a crash compared with other age groups (Leonardi et al., 2019); this is because they have a greater tendency to be involved in distracting activities (Olsen et al., 2005). Many researchers have studied some distracting factors that influence drivers' reaction times (Horberry et al, 2006; Patten et al., 2004; Strayer and Johnston, 2001; Ronzhina et al., 2012).

The second part of the vehicle's stopping time is the braking time that is determined from the moment the driver applies the brake to the moment the car stops (Evans and Pitkethly, 2011). It is influenced by the vehicle's speed, the tires' design (Rievaj et al., 2013), the road situation, the load (vehicle's weight), and the "brakes condition, as well as the brake technology and how many wheels are braking" (KORKORT, 2018). The friction between the automobile's tires and the road plays an important role to estimate the braking distance. The friction coefficient was well reported in (Al-Grafi et al., 2013) and is between 0.7 and 0.4 for dry and wet roads, respectively.

A simple road accident event that occurs when one car hits another car shows that the reaction and braking time are not only variables that must be calculated, but also factors that help to identify the responsibility of the participants in the accident (Magister et al., 2006). The total stopping distance is calculated using the following formula (Magister et al., 2006; Fattah, 1990):

$$
s=v_{o} t_{r}+\left(v_{o}^{2}-v_{f}^{2}\right) / 2 a
$$

where $\mathrm{s}$ is the stopping distance $(\mathrm{m})$, a is the car deceleration $\left(\mathrm{m} / \mathrm{s}^{2}\right), v_{o}$ is the car initial speed before braking $(\mathrm{m} / \mathrm{s}), v_{f}$ is the car speed at impact moment $(\mathrm{m} / \mathrm{s})$, and $t_{r}$ is the driver's reaction time (s). From Equation (1), the sopping distance can be evaluated if the driver's RT, and vehicle's initial velocity $\left(v_{o}\right)$ and deceleration $(a)$ are known. For example, if the driver's reaction time is ranged from 0.4 to $1.8 \mathrm{~s}$, the car deceleration is 4 $\mathrm{m} / \mathrm{s}^{2}$, and the car speed is $72 \mathrm{~km} / \mathrm{h}$, then the stopping distance is fluctuated between 58 and $86 \mathrm{~m}$. This will help the accident reconstruction experts 'persist' to reconstruct road accidents almost without an exception. It is also possible to calculate the initial speed of the vehicle by solving Equation (1) to be (Magister et al., 2006)

$$
v_{o}=-a t_{r}+\sqrt{v_{f}^{2}+2 a s+a^{2} t_{r}^{2}}
$$

The reaction time of the driver in several driving circumstances is well labeled in literature (Olson, 1989; Limpert, 1984; Dilich et al., 2002; Seymour-Hart, 2000). However, the stopping time and distance databases are not published in the respective literature. Furthermore, the evaluation of stopping distance based on the driver's age and gender is not taken in consideration. The main objective of this paper is to define accident system and drivers' RTs effect on it. The paper also aims to find the effects of drivers' 
age and gender, and their impact on the vehicle's stopping distance under various speeds. First, the paper gives fundamental information on the methodology used in this study. This is followed by statistical analyses and discussions of the obtained results; and finally the conclusion of the work is demonstrated.

\section{Methodology}

Design of the study: A descriptive study is executed on a total of 410 applicants (189 females), ranging in five age groups participated in this study: A1 (age 18-28), A2 (age 29-39), A3 (age 40-50), A4 (age 51-61), and A5 (62 and more) years-old. All participants had driving license from the Iraqi Traffic Department. They also had normal vision and had no a history of neurological diseases. Informed agreement was acquired from all contributors.

Method of data collection: Data was collected through test the participants on a reaction time simulator that was designed and implemented by Allen (2002) at the University of Washington to calculate the reaction time. Each participant sat on a chair that had a fixed distance from a monitor screen. The instruction was to keep their eyes on the stoplight area on the screen and react when the light was changed from red to green by moving hand and pressing a corresponding button on the screen as shown in Figure 1. Each participant performed five testes and then the average reaction time was recorded. Then, the reaction time was used to determine the vehicle stopping distance (reaction distance) that is traveled during the reaction time using the following formula

$$
s_{r}=v_{o} * t_{r}
$$

where $s_{r}$ is the distance during the driver's reaction time $(\mathrm{m}), v_{o}$ is the initial speed of the vehicle $(\mathrm{m} / \mathrm{s})$, and $t_{r}$ is the driver's reaction time (Fattah, 1990). Braking distance can be calculated as follows:

$$
s_{b}=\frac{1}{2} * v_{o} t_{b}
$$

where $s_{b}$ is the braking distance $(\mathrm{m})$, and $t_{b}$ is the braking time (Fattah, 1990). It is known from kinematics that

$$
v_{f}^{2}=v_{o}^{2}+2 a \Delta s
$$

where $a$ is the constant acceleration rate $(\mathrm{m} / \mathrm{s} 2)$; and $\Delta s$ is the distance covered during the motion. In case of applying the brake, the final velocity $v_{f}=0$ and the magnitude of the deceleration will be (Fattah, 1990)

$$
a=v_{o}^{2} / 2 s_{b}
$$

From Newton's second low, it can be conclude that

$$
a=F_{f} / \mathrm{m}
$$

where $F_{f}$ and $\mathrm{m}$ are the total frictional force and the vehicle's mass, respectively. The frictional force of the vehicle can be calculated from (Mungan, 2012)

$$
F_{f}=\mu N=\mu m g
$$

where $\mathrm{N}, \mu$ and $g$ are the sum of the normal forces of all four wheels, the coefficient of kinetic friction, and the acceleration of gravity. Then, the vehicle deceleration is calculated by substituting Equation 8 for Equation 7 to yield (Kajackas, 2015) 


$$
a=\mu g
$$

It is possible to calculate the braking distance from the deceleration rate, after adding a line ratio of up to $4 \%$ by applying the following formula (Fattah, 1990; Mamdoohi et al., 2014):

$$
s_{b}=v_{o}^{2} / 2 a
$$

This equation determines the braking distance, when the initial speed and the state of deceleration are known. Finally the stopping distance is determined using the following rule

$$
\begin{aligned}
& \text { Stopping distance }=\text { Reaction distance }+ \text { Braking distance } \\
& \quad s=s_{r}+s_{b}
\end{aligned}
$$

\begin{tabular}{|c||l||l||l||}
\hline $\begin{array}{l}\text { Test } \\
\text { Number }\end{array}$ & $\begin{array}{l}\text { Reaction } \\
\text { Time }\end{array}$ & $\begin{array}{l}\text { The stoplight } \\
\text { to watch. }\end{array}$ & $\begin{array}{l}\text { The button } \\
\text { to click. }\end{array}$ \\
\hline 1 & 1.18 & \\
\hline 2 & 0.478 \\
\hline 3 & 0.876 \\
\hline 4 & 0.962 & \\
\hline 5 & 0.502 \\
\hline AVG. & 0.7995999999999999 \\
\hline
\end{tabular}
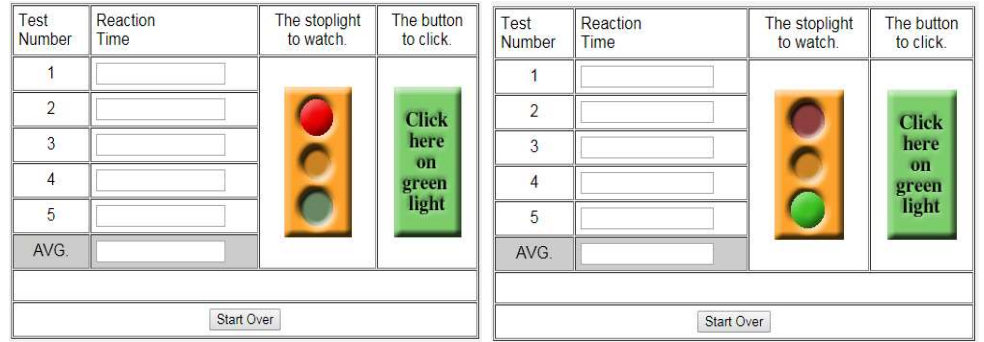

Figure 1: The reaction time simulator

Data Statistical Analyses (Approach of Statistic): The "Statistical Package for the Social Sciences", called (IBM SPSS -version 23) was used to find the significance of participants' ages and genders on their reaction time. The information of statistical analysis approaches was used to analyze and estimate the consequences of the study:

- The Descriptively Approach

Statistical tables "Frequencies and percent" which are:

$$
\%=\frac{\text { Frequency }}{\text { Sample Size }} \times 100
$$

- The Inferentially Approach Data Analysis

* Chi-Squared Test was used to test the difference between the numbers of nominal standards of random variables.

$$
\chi^{2}=\frac{\sum_{\text {all }}\left(\mathrm{O}_{\mathrm{i}}-\mathrm{E}_{\mathrm{i}}\right)^{2}}{\mathrm{E}_{\mathrm{i}}}
$$

where " X2 ", " $\sum$ ", $\mathrm{O}_{\mathrm{i}}$, and $\mathrm{E}_{\mathrm{i}}$ are the chi-squared, the summation, the observed frequency of group $\mathrm{i}$, and the expected frequency; respectively.

- The Analysis of Variance (ANOVA) with Microsoft Excel was employed to find the effects of the participants' ages and genders on the vehicle's stopping distance under different speeds.

They $\chi^{2}$ obs. $<\chi^{2}$ crit. $=$ insignificantly. $\quad$ As compared with the Degree of They $\chi^{2}$ obs. $>\chi^{2}$ crit. $=$ significantly, freedom d.f 


\section{Results and Discussion}

Table 1: Distribution of Study Sample by their Demographic Characteristics

\begin{tabular}{|c|c|c|c|}
\hline Demographic data & Rating & No. & $\%$ \\
\hline \multirow{6}{*}{ Age (years) } & $18-28$ & 90 & 22.0 \\
\hline & $29-39$ & 91 & 22.2 \\
\hline & $40-50$ & 85 & 20.7 \\
\hline & $51-61$ & 80 & 19.5 \\
\hline & $62+$ & 64 & 15.6 \\
\hline & Total & 410 & 100 \\
\hline \multirow{3}{*}{ Gender } & Male & 221 & 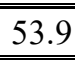 \\
\hline & Female & 189 & 46.1 \\
\hline & Total & 410 & 100 \\
\hline \multirow{4}{*}{ Reaction Time } & $(0.443-0.750)$ & 96 & 23.4 \\
\hline & $(0.751-1.000)$ & 149 & 36.3 \\
\hline & $(1.001+)$ & 165 & 40.2 \\
\hline & Total & 410 & 100 \\
\hline
\end{tabular}

$\%$ : percentage, No.: number of participants

Table 1 reveals that $22.2 \%$ of the study sample was within age group 29-39 years old. Concerning gender, the results depict that $53.9 \%$ were males and the remaining females. Regarding reaction time, the reaction of $40.2 \%$ participants were more than 1 second, while $23.4 \%$ of the participants were at $0.443-0.750$ as a part of second.

Table 2: Statistical of Participants Reaction Time in Relation to their Age and Gender

\begin{tabular}{|c|c|c|c|c|c|c|c|c|}
\hline \multirow{2}{*}{ Variables } & \multirow{2}{*}{ Rating } & \multicolumn{3}{|c|}{ Reaction Time } & \multirow{2}{*}{ Total } & \multirow{2}{*}{$\chi^{2}$ obs. } & \multirow{2}{*}{ D.f } & \multirow{2}{*}{$\chi^{2}$ crit. } \\
\hline & & $(0.443-0.750)$ & $(0.751-1.000)$ & $(1.001+)$ & & & & \\
\hline \multirow{7}{*}{ Age (years) } & $18-28$ & 58 & 29 & 3 & 90 & \multirow{6}{*}{103.897} & \multirow{6}{*}{8} & \multirow{6}{*}{15.507} \\
\hline & $29-39$ & 31 & 49 & 11 & 91 & & & \\
\hline & $40-50$ & 7 & 46 & 32 & 85 & & & \\
\hline & $51-61$ & 0 & 21 & 59 & 80 & & & \\
\hline & $62+$ & 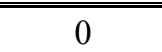 & 4 & 60 & 64 & & & \\
\hline & Total & 96 & 149 & 165 & 410 & & & \\
\hline & \multicolumn{8}{|c|}{$P$-value $=0.000 \rightarrow H S$} \\
\hline \multirow{4}{*}{ Gender } & Male & 67 & 84 & 70 & 221 & \multirow{3}{*}{7.604} & \multirow{3}{*}{2} & \multirow{3}{*}{5.991} \\
\hline & Female & 29 & 65 & 95 & 189 & & & \\
\hline & Total & 96 & 149 & 165 & 410 & & & \\
\hline & \multicolumn{8}{|c|}{$P$-value $=0.022 \rightarrow S$} \\
\hline
\end{tabular}

$\chi^{2}$ obs. $=$ Chi-square observer, $\chi^{2}$ crit. $=$ Chi-square critical, d.f $=$ Degree of freedom, $\mathrm{P}$-value $=$ Probability value NS : Non significantly at probability-value P-value $>0.05$., $\mathrm{S}$ : Significantly at probability-value $\mathrm{P}$-value $<0.05$., HS : Highly significantly at probability-value $\mathrm{P}$-value $<0.01$. 
Table 2 illustrates the statistical analysis of participants' reaction time in relation to their age and gender. It can be seen from the analysis that participants' reaction times had high significant relationship with their age at p-value $(<0.01)$. Also, the participants' gender is significantly associated with reaction time at p-value $(<0.05)$. The measurements of the reaction times within the age groups were relatively different, in which drivers' reaction time increased as their age increased. This study shows that most participants who were in fourth and fifth group reacted more than 1 second in comparison with the participants of the first and second group. This might be due to a perceptual reason related to the extent of vision and concentration as stated in (Porciatti et al., 1999). This is in agreement with Der and Deary, 2006 who confirmed that "Reaction times (RTs) becomes more flexible with age" and "there are significant sex differences, most notably for choice RT variability".

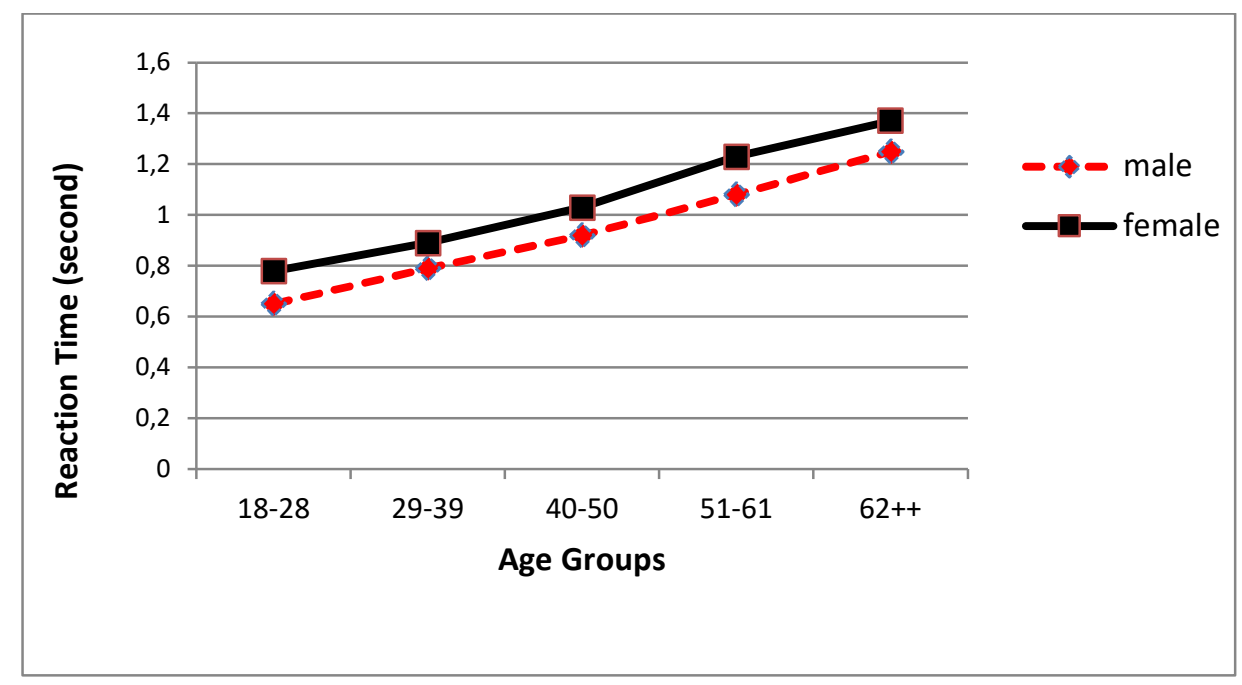

Figure 2: The relationship of the participants' average reaction times with their ages and genders within each group.

Figure 2 demonstrates the relationship of the participants' average reaction times with their ages and genders. It can be seen from the plot that in all age groups, the reaction times increased as the drivers' age increased, and the females' reaction times were longer than males' in all age groups. According to Dykiert et al., 2012, "It is plausible that sex hormones, which come into play at puberty has different effects on male and female brains". This finding supports a previous research conducted by Leonardi et al., 2019 who states that "females perceive a slightly higher risk than males"; and this means "The women" category is close to the "High Risk" category, while the men category is closer to the "Medium Risk" category.

As mentioned above, the participants were divided into five categories and the measurements of their reaction times were done in the simulated driving environment. The reaction, braking and stopping distances were then determined using five different initial speeds $(36,54,72,108$, and 144$) \mathrm{km} / \mathrm{h}$. The vehicle's deceleration was calculated using Equation 9 and by assuming $\mu$ and $g$ to be 0.6 and $9.81 \mathrm{~m} / \mathrm{s}^{2}$ in all calculations. Then, the reaction and braking distances were calculated using Equations 3 and 10, respectively. Table 3 shows the summary results of the calculations of average distances of males and females' reaction time. Note that the vehicle's braking distance is constant 
for male and female as it is influenced by the vehicle's speed, tires' design (Rievaj et al., 2013), road situations, and the brakes condition (KORKORT, 2018). The stopping distance was determined using Equation 11; these distances were used to find the relationship of drivers' ages and genders and the vehicle's stopping distance under each speed.

It can be seen from Table 3 that the reaction time plays a significant role in minimizing the stopping distance; especially within high speed. For instance, in order to stop a vehicle moving at $144 \mathrm{~km} / \mathrm{h}$, the male drivers in fifth group need $186 \mathrm{~m}$ in comparison with the drivers in first group who need $162 \mathrm{~m}$ as stopping distance. Such differences in stopping distance can actually be a matter of life and death in most cases.

Table 3: Experimental results of calculations of the stopping distance at different speeds using the average driver's reaction time (malesand females): A1, A2, A3, A4, and A5 indicts participants in (18-28), (29-39), (40-50), (51-61), and (62 and more) years-old, respectively.

\begin{tabular}{|c|c|c|c|c|c|c|c|c|}
\hline $\begin{array}{c}\text { The car } \\
\text { speed } \\
(\mathrm{km} / \mathrm{h})\end{array}$ & Age Group & $\begin{array}{c}\text { Braking } \\
\text { distance }(m)\end{array}$ & $\begin{array}{l}\text { Average } \\
\text { Males' } \\
\text { Reaction } \\
\text { time (s) }\end{array}$ & $\begin{array}{l}\text { Average } \\
\text { females' } \\
\text { Reaction } \\
\text { time (s) }\end{array}$ & $\begin{array}{c}\text { Males }^{\prime} \\
\text { Reaction } \\
\text { distance }(m)\end{array}$ & $\begin{array}{c}\text { Females' } \\
\text { Reaction } \\
\text { distance }(m)\end{array}$ & $\begin{array}{c}\text { Males' }^{\prime} \\
\text { Stopping } \\
\text { distance }(m)\end{array}$ & $\begin{array}{c}\text { Females' } \\
\text { Stopping } \\
\text { distance }(m)\end{array}$ \\
\hline \multirow{5}{*}{36} & A1 & 8.49 & 0.65 & 0.78 & 6.5 & 7.8 & 14.99 & 16.29 \\
\hline & A2 & 8.49 & 0.79 & 0.89 & 7.9 & 8.9 & 16.39 & 17.39 \\
\hline & A3 & 8.49 & 0.92 & 1.03 & 9.2 & 10.3 & 17.69 & 18.79 \\
\hline & A4 & 8.49 & 1.08 & 1.23 & 10.8 & 12.3 & 19.29 & 20.79 \\
\hline & A5 & 8.49 & 1.25 & 1.37 & 12.5 & 13.7 & 20.99 & 22.19 \\
\hline \multirow{5}{*}{54} & A1 & 19.11 & 0.65 & 0.78 & 9.75 & 11.7 & 28.86 & 30.81 \\
\hline & $\mathrm{A} 2$ & 19.11 & 0.79 & 0.89 & 11.85 & 13.35 & 30.96 & 32.46 \\
\hline & A3 & 19.11 & 0.92 & 1.03 & 13.8 & 15.45 & 32.91 & 34.56 \\
\hline & A4 & 19.11 & 1.08 & 1.23 & 16.2 & 18.45 & 35.31 & 37.56 \\
\hline & A5 & 19.11 & 1.25 & 1.37 & 18.75 & 20.55 & 37.86 & 39.66 \\
\hline \multirow{5}{*}{72} & A1 & 33.98 & 0.65 & 0.78 & 13 & 15.6 & 46.98 & 49.58 \\
\hline & $\mathrm{A} 2$ & 33.98 & 0.79 & 0.89 & 15.8 & 17.8 & 49.78 & 51.78 \\
\hline & A3 & 33.98 & 0.92 & 1.03 & 18.4 & 20.6 & 52.38 & 54.58 \\
\hline & A4 & 33.98 & 1.08 & 1.23 & 21.6 & 24.6 & 55.58 & 58.58 \\
\hline & A5 & 33.98 & 1.25 & 1.37 & 25 & 27.4 & 58.98 & 61.38 \\
\hline \multirow{5}{*}{108} & A1 & 76.45 & 0.65 & 0.78 & 19.5 & 23.4 & 95.95 & 99.85 \\
\hline & $\mathrm{A} 2$ & 76.45 & 0.79 & 0.89 & 23.7 & 26.7 & 100.15 & 103.15 \\
\hline & A3 & 76.45 & 0.92 & 1.03 & 27.6 & 30.9 & 104.05 & 107.35 \\
\hline & A4 & 76.45 & 1.08 & 1.23 & 32.4 & 36.9 & 108.85 & 113.35 \\
\hline & A5 & 76.45 & 1.25 & 1.37 & 37.5 & 41.1 & 113.95 & 117.55 \\
\hline \multirow{5}{*}{144} & A1 & 135.92 & 0.65 & 0.78 & 26 & 31.2 & 161.92 & 167.12 \\
\hline & $\mathrm{A} 2$ & 135.92 & 0.79 & 0.89 & 31.6 & 35.6 & 167.52 & 171.52 \\
\hline & A3 & 135.92 & 0.92 & 1.03 & 36.8 & 41.2 & 172.72 & 177.12 \\
\hline & A4 & 135.92 & 1.08 & 1.23 & 43.2 & 49.2 & 179.12 & 185.12 \\
\hline & A5 & 135.92 & 1.25 & 1.37 & 50 & 54.8 & 185.92 & 190.72 \\
\hline
\end{tabular}

The Analysis of Variance (ANOVA) was conducted to compare the effect of predictors' ages, genders, and vehicle's speeds on the vehicles stopping distances. It was found that the predictors account for $98 \%$ of the variance in vehicle's stopping distance. The overall regression model presented that the predictors have a high significant effect on the stopping distance as $\mathrm{F}(3,46)=777.05$, P-value $<0.001$, and R-square $=0.98$. However, gender independently was not significant, as its $\mathrm{P}$-value $>0.24$ as shown in 
Table 4. It should be noted that the vehicle's speed has very high significant effect as Pvalue $<0.001$.

Table 4: The analysis of variance (ANOVA) table in MS excels

\begin{tabular}{|c|c|c|c|c|c|c|c|c|}
\hline & Coefficients & $\begin{array}{c}\text { Standard } \\
\text { Error }\end{array}$ & $t$ Stat & P-value & $\begin{array}{c}\text { Lower } \\
95 \%\end{array}$ & $\begin{array}{c}\text { Upper } \\
95 \%\end{array}$ & $\begin{array}{c}\text { Lower } \\
95.0 \%\end{array}$ & $\begin{array}{c}\text { Upper } \\
95.0 \%\end{array}$ \\
\hline Intercept & -58.17212 & 5.15873 & -11.27645 & 0.00000 & -68.556 & -47.788 & -68.556 & -47.788 \\
\hline $\begin{array}{c}\text { Age } \\
\text { Group }\end{array}$ & 3.46150 & 0.83553 & 4.14288 & 0.00015 & 1.780 & 5.143 & 1.780 & 5.143 \\
\hline $\begin{array}{c}\text { Vehicle's } \\
\text { speed }\end{array}$ & 1.46553 & 0.03048 & 48.08925 & 0.00000 & 1.404 & 1.527 & 1.404 & 1.527 \\
\hline Gender & 2.80600 & 2.36324 & 1.18735 & 0.24118 & -1.951 & 7.563 & -1.951 & 7.563 \\
\hline Intercept & -58.17212 & 5.15873 & -11.27645 & 0.00000 & -68.556 & -47.788 & -68.556 & -47.788 \\
\hline $\begin{array}{c}\mathrm{R} \\
\text { Square }\end{array}$ & 0.98 & & & & & & & \\
\hline
\end{tabular}

Figure 3 shows a comparison of drivers' ages and genders with the stopping distance under five different speeds. . It can be seen that the stopping distance increase with the increase of drivers' age and this finding supports a previous research conducted by Ahn et al., 2019. Ball et al. (2006) states that older drivers are higher risk of crash involvement because of their slower responses coupled with "visual and cognitive impairment" due to aging. It is also seen that females require a slightly higher stopping distance than males. This is in agreement with the study by Kweon and Kockelman (2003) who found female are more at risk than male drivers. However, the initial speed has a certain effect on the vehicle's stopping distance, regardless of the driver's age and gender. For instance, the male and female drivers in group $\left(\mathrm{A}_{1}\right)$ need about 15 and $16 \mathrm{~m}$ of stopping distance to stop a vehicle under $36 \mathrm{~km} / \mathrm{h}$, while they need about 162 and $167 \mathrm{~m}$ for a vehicle at a speed of $144 \mathrm{~km} / \mathrm{h}$.

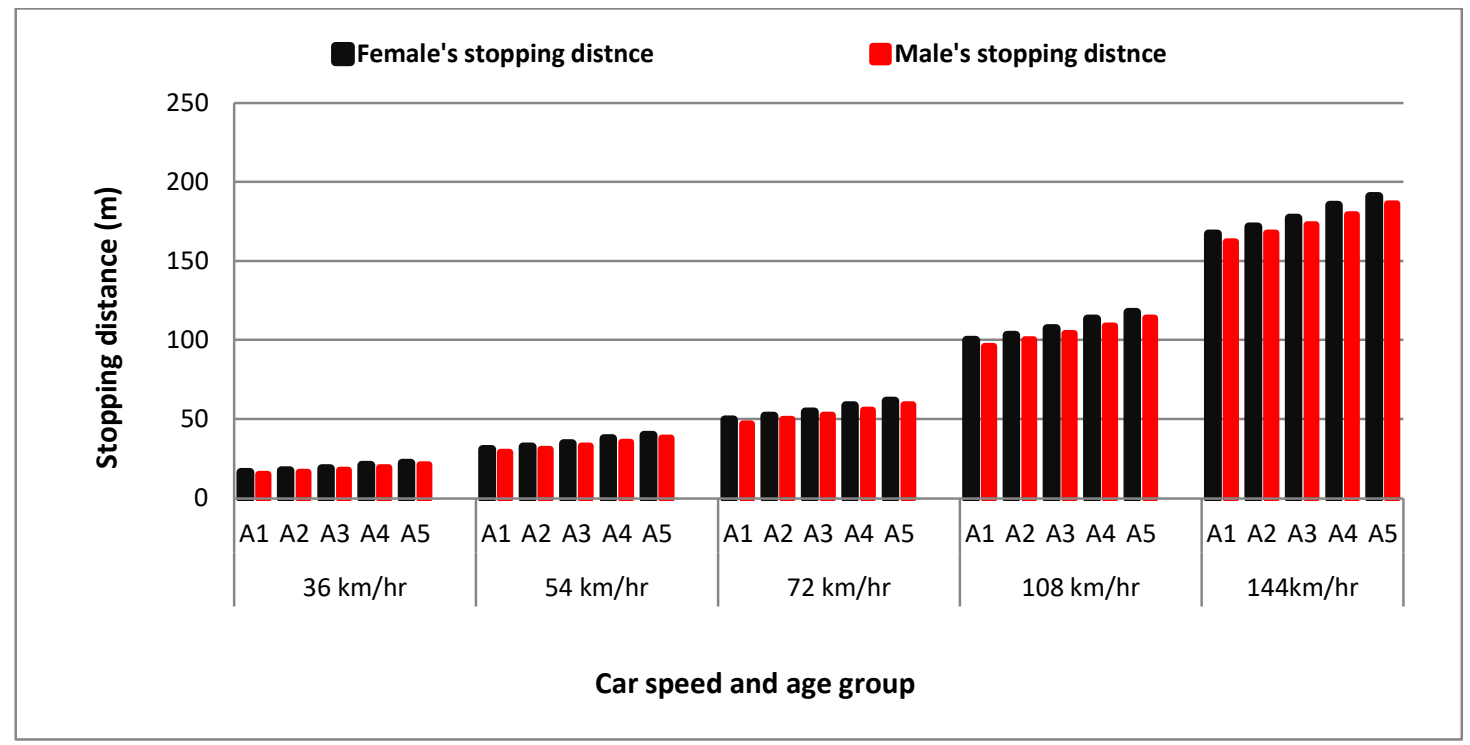

Figure 3: The relationship of male and female ages on vehicle's stopping distances under each initial speed. 
Figure 4 shows the relationship between the vehicle's speeds and stopping distances for males and females that was plotted using Excel program. The equation of relationship curve could be found using Excel's trend/regression analysis and it was deduced to be

$$
s_{S}=10.412 e^{0.0205 v_{0}}
$$

The regression model on Figure 4 accounts for $95.7 \%$ of the variance. This equation evaluates the stopping distance of vehicle at assumptions mentioned above.

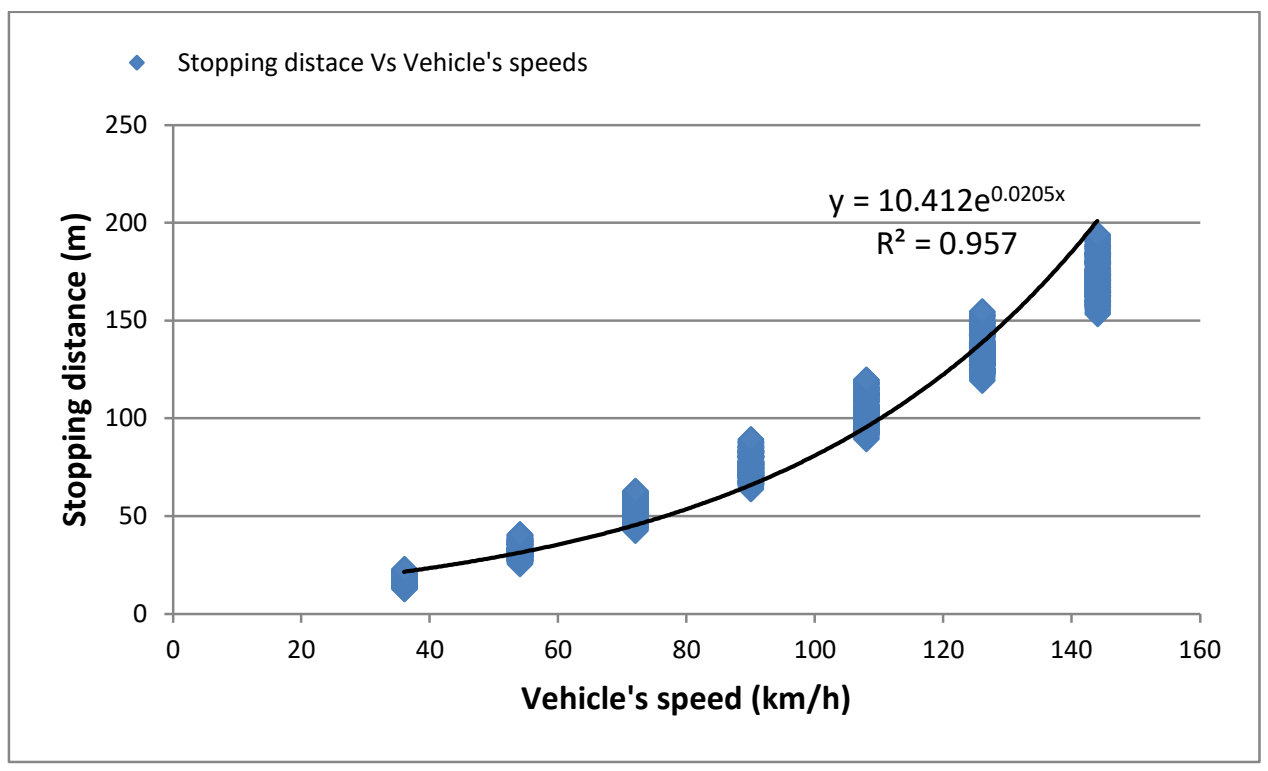

Figure 4: Driving performance as a function of the vehicle's speeds and stopping distances

\section{Conclusion}

The paper investigates the possible effect of the driver's age and gender on the vehicle's stopping distance under different speeds. First, an analysis of the measured reaction times of the drivers was executed to find the influences of the drivers' gender and age on their responses. The analysis of variance (ANOVA) was executed to compare the effect of the predictors' ages, genders, and vehicle's speeds on the vehicle's stopping distances. From the analyzed results, it was concluded that:

1- The participants' reaction time is significantly related to their ages; thus, the reaction time increases as the age increases.

2- The participants' gender significantly is associated with reaction time, the results indicate that females have longer reaction time than males.

3- The overall regression model showed a high significant effect of the predictors on stopping distance; however, the gender individually was not significant. In this case, the females need slightly higher stopping distances than males.

4- The age differences have a slightly higher effect on a vehicle's stopping distance.

5- The vehicle's speed has very high significant effect on the vehicle stopping distance, regardless of the driver's age and gender. 


\section{References}

Ahn, J.Y., Ryoo, H.W., Park, J. K., Lee, M. J., Lee, D.E., Seo K.S., Kim, Y.J., and Moon, S. (2019). "Comparison of Traffic collision victims between older and younger drivers in south Korea: Epidemiologic characteristics, risk factors and types of collision." PLoS one, Vol. 14(4).

Al-Grafi M. W., Mohamed M. K., and Salem F. A. (2013). "Analysis of vehicle friction coefficient by simulink with Matlab." International Journal of Control Automation and Systems, VOL. 2(2), pp. 55-60.

Allen J., "The Online Reaction Time Test," (2002), Available from: https://faculty.washington.edu/chudler/java/redgreen.html [Accessed 22th October 2018]

Ball KK, Roenker DL, Wadley VG, Edwards JD, Roth DL, McGwin G Jr, et al. (2006). "Can high-risk older drivers be identified through performance-based measures in a Department of Motor Vehicles setting?" J Am Geriatr Soc., Vol. 54(1), pp. 77-84.

Bucsuházy K., and Semela M. (2017). "Case study: reaction time of children according to age." Procedia engineering, Vol. 187, pp.408-413.

Deary I. J., and Der G. (2005) "Reaction time, age, and cognitive ability: Longitudinal findings from age 16 to 63 years in representative population samples." Aging, Neuropsychology, and cognition Vol. 12(2) pp. 187-215.

Der G., and Deary I.J (2006). "Age and Sex Differences in Reaction Time in Adulthood: Results from the United Kingdom Health and Lifestyle Survey," Psychology and aging, Vol. 21(1), pp.62-73.

Dilich, M. A., Kopernik D., and Goebelbecker J. (2002). "Evaluating Driver Response to a Sudden Emergency: Issues of Expectancy, Emotional Arousal and Uncertainty." Journal Of Passenger Car: Mechanical Systems Journal, Vol. 111(6), pp. 238-248.

Dykiert D., Der G., Starr J.M., and Deary I.J. (2012). "Sex Differences in Reaction Time Mean and Intraindividual Variability across the Life Span." Developmental psychology, Vol. 48(5), pp.1262-1276.

Evans M. and Pitkethly J. (2011). "Braking distance." Australian Mathematical Sciences Institute, The University of Melbourne.

Fattah S. S. (1990). "The Theory of Cars. " University of Technology-Baghdad, Second Edition.

Horberry, T., Anderson, J., Regan, M.A., Triggs, T.J., and Brown, J. (2006). "Driver distraction: The effects of concurrent in-vehicle tasks, road environment complexity and age on driving performance." Accident Analysis \& Prevention, Vol. 38(1), pp.185-191.

Hultsch D. F., Macdonald S., and Dixon R. A. (2002). "Variability in Reaction Time Performance of Younger and Older Adults." The Journals of Gerontology Series B: Psychological Sciences and Social Sciences, Vol. 57(2), pp. 101-115.

IBM SPSS software, https://www.ibm.com/analytics/spss-statistics-software

Inui N. (1997). "Simple Reaction Times and Timing of Serial Reactions of Middle-Aged and Old Men." Perceptual and Motor Skills, Vol. 84, pp. 219-225.

Kajackas A., Žuraulis V., and Sokolovskij E. (2015). "Influence of VANET System on Movement of Traffic Flows in Emergency Situations." Promet - Traffic \& Transportation, Vol. 27(3), pp. 237-246. 
KORKORT online.se, Available from: https://korkortonline.se/en/theory/reactionbraking-stopping/ [Accessed 22th October 2018]

Kweon Y-J, and Kockelman KM. (2003). "Overall injury risk to different drivers: combining exposure, frequency, and severity models." Accident Analysis \& Prevention, Vol. 35(4), pp. 441-50.

Leonardi S., Distefano N., and Pulvirenti G. (2019). "Multiple Correspondence Analysis (MCA) for the evaluation of risk perception of roundabouts for young people." European Transport, Issue 72.

Limpert, R. (1984). "Motor Vehicle Accident Reconstruction and Cause Analysis." Fifth edition. Lexis, Virginia, US, pp. 429-438.

Magister T., Batista M., Krulec R., and Bogdanovic L. (2006). "Measurement of the Driver Response Time in the Simulated and Real Emergency Driving Situations." Promet-Traffic\& Transportation, Vol. 18(1), pp. 23-32.

Mamdoohi A. R., Zavareh M. F., Hydén C., and Nordfjærn T. (2014). "Comparative Analysis of Safety Performance Indicators Based on Inductive Loop Detector Data." Promet-Traffic \& Transportation, Vol. 26(2), pp. 139-149.

Mungan C. E. (2012). "Rolling Friction on a Wheeled Laboratory Cart." Physics Education, Vol. 47(3), pp. 288-292.

Olsen, E. C. B., Lerner, N., Perel, M., and Simmons-Morton, B. G. (2005). "In-car electronic device use among teen drivers." Proc., 84th Annual Meeting of the Transportation Research Board, Transportation Research Board, Washington, D.C.

Olson P. L. (1989). "Driver perception response time." SAE Technical Papers 890731.

Patten C.J., Kircher A., Östlund J., and Nilsson L. (2004). "Using mobile telephones: cognitive workload and attention resource allocation." Accident analysis \& prevention, Vol. 36(3), pp.341-350.

Porciatti V., Fiorentini A., Morrone M. C., and Burr D. C. (1999). "The Effects of Ageing on Reaction Times to Motion Onset." Vision research, Vol. 39(12), pp. 2157-2164.

Rievaj V., Vrábel J., and Hudák A. (2013). "Tire Inflation Pressure Influence on a Vehicle Stopping Distances." International Journal of Traffic and Transportation Engineering, Vol. 2(2), pp. 9-13.

Ronzhina, M., Janoušek, O., Kolářová, J., Nováková, M., Honzík, P., and Provazník, I. (2012). "Sleep scoring using artificial neural networks." Sleep medicine reviews, Vol. 16(3), pp.251-263.

Seymour-Hart, I. I. (2000). "Road traffic accident reconstruction: Vision, alertness and reaction relating to driving." SAE Technical Papers.

Strayer D. L, and Johnston W. A. (2001). "Driven to distraction: Dual-task studies of simulated driving and conversing on a cellular telephone." Psychological science, Vol. 12(6), pp. 462-466. 